\title{
SMAD7 rs4939827 variant contributes to colorectal cancer risk in Chinese population
}

\author{
Chunze Zhang ${ }^{1, *}$, Xichuan Li ${ }^{2,}{ }^{*}$, Wenzheng Fu' ${ }^{1}$, Yijia Wang ${ }^{3}$, Tao Wang ${ }^{1}$, Wenhong \\ Wang $^{4}$, Shuo Chen ${ }^{1}$, Hai Qin ${ }^{1}$ and Xipeng Zhang ${ }^{1}$ \\ ${ }^{1}$ Department of Colorectal Surgery, Tianjin Union Medical Center, Tianjin 300121, China \\ ${ }^{2}$ Department of Immunology, Biochemistry and Molecular Biology, 2011 Collaborative Innovation Center of Tianjin for Medical \\ Epigenetics, Tianjin Key Laboratory of Medical Epigenetics, Tianjin Medical University, Tianjin 300070, China \\ ${ }^{3}$ Department of Pathology, Tianjin Union Medical Center, Tianjin 300121, China \\ ${ }^{4}$ Department of Imaging, Tianjin Union Medical Center, Tianjin 300121, China \\ *These authors have contributed equally to this work \\ Correspondence to: Xipeng Zhang, email: xipengzhangtj@163.com, zhangxipengtj@163.com
}

Keywords: colorectal cancer, SMAD7, rs4939827, meta-analysis

Received: November 04, $2016 \quad$ Accepted: March 11, $2017 \quad$ Published: April 12, 2017

Copyright: Zhang et al. This is an open-access article distributed under the terms of the Creative Commons Attribution License (CCBY), which premits understricted use, distribution, and reproduction in any medium, provided the original author and source are credited.

\section{ABSTRACT}

A genome-wide association study identified a common genetic variant rs4939827 at 18q21 in SMAD7 to be related with colorectal cancer (CRC) risk with $O R=1.2$ and $P=7.80 E-28$. Until recently, several meta-analysis studies have been conducted, and reported significant association between rs4939827 and CRC risk. However none of these studies evaluated the potential association between rs4939827 and CRC risk in Chinese population. In this study, we evaluated this association by a meta-analysis using 12077 samples including 5816 CRC cases and 6261 controls. In the end, we identified the $T$ allele of rs4939827 to be significantly related with an increase CRC risk $(P=2.22 E-05, O R=1.14,95 \% C I 1.07-1.21)$ in Chinese population.

\section{INTRODUCTION}

It is reported that colorectal cancer (CRC) is the third most common type of cancer and the leading cause of cancer death, which could cause about 600,000 deaths in the world annually [1-2]. Evidence shows that CRC is a common human complex disease, which is considered to be caused by the interactions between genetic variants and environmental factors [1-2]. It is reported that some factors including allele frequencies, specific linkage disequilibrium structure, and special genetic and environmental backgrounds may cause the risk alleles variation to $\mathrm{CRC}$ risk in different populations [3]. Meanwhile, evidence showed racial differences in the incidence of colorectal cancer [4-6]. The incidence in native Chinese is significantly lower than in Chinese-Americans, who have similar rates with the native Americans [5]. Virk et al. reported the significant differences in the incidence of colorectal cancers in various racial subgroups in British Columbia [5]. The incidence in Chinese Canadians population is significantly lower than in Caucasian Canadians and South Asian Canadians [5]. There are also different survival and clinicopathologic features in colorectal cancer in African American, Caucasian, and Chinese patients [7]. All these findings indicate that it is still necessary to evaluate a specific variant in a specific population, which would be informative to reveal the disease mechanism [3].

Since 2007, several large-scale genome-wide association studies (GWAS) have been performed to detect common CRC genetic variants [8-14]. In these above studies, Tenesa et al. identified a common genetic variant rs4939827 at 18q21 in SMAD7 to be associated with CRC risk with $\mathrm{OR}=1.2$ and $P=7.80 \mathrm{E}-28$ [9].

To further verify the original finding from above study, some genetic association studies have investigated the association between rs4939827 and CRC risk in other populations. However these studies reported both positive and negative association results. Until recently, several meta-analysis studies have also been conducted, and reported significant association between rs4939827 and CRC risk [15-17]. However none of these studies evaluated the potential association between rs4939827 and 
Table 1: Main characteristics of 6 studies

\begin{tabular}{|c|c|c|c|c|c|c|c|c|c|c|c|c|}
\hline Study & Year & Allele & MAF & $\begin{array}{c}\text { OR } \\
{[95 \% \mathrm{CI}]}\end{array}$ & Population & Ethnicity & Cases & Controls & $\begin{array}{l}\text { Family } \\
\text { history }\end{array}$ & Mean age & HWE & $P$ value \\
\hline $\begin{array}{l}\text { Xiong } \\
{[19]}\end{array}$ & 2010 & T vs. C & 0.17 & $\begin{array}{c}1.17 \\
{[1.05-1.31]}\end{array}$ & Han Chinese & Han & 2124 & $2124(\mathrm{P})$ & NA & $\begin{array}{l}56.9 \pm 11.8 \text { in } \\
\text { cases } \\
56.4 \pm 11.3 \text { in } \\
\text { controls }\end{array}$ & Yes & $5.70 \mathrm{E}-03$ \\
\hline Ho [20] & 2011 & T vs. C & 0.35 & $\begin{array}{c}1.18 \\
{[1.01-1.38]}\end{array}$ & $\begin{array}{c}\text { Hong Kong } \\
\text { Chinese }\end{array}$ & NA & 892 & $890(\mathrm{H})$ & No & $\begin{array}{c}66.75 \pm 12.25 \\
\text { in cases in } \\
\text { phase } 1 \\
66.43 \pm 12.21 \\
\text { in cases in } \\
\text { phase } 2\end{array}$ & Yes & 0.037 \\
\hline $\operatorname{Li}[21]$ & 2011 & T vs. C & 0.26 & $\begin{array}{c}0.90 \\
{[0.63-1.28]}\end{array}$ & Han Chinese & Han & 138 & 168 (NA) & NA & $\begin{array}{c}52.53 \pm 13.405 \\
\text { in cases } \\
59.26 \pm 15.854 \\
\text { in controls }\end{array}$ & Yes & 0.771 \\
\hline $\begin{array}{l}\text { Song } \\
{[15]}\end{array}$ & 2012 & T vs. $\mathrm{C}$ & 0.20 & $\begin{array}{c}1.26 \\
{[1.05-1.51]}\end{array}$ & Han Chinese & Han & 641 & $1037(\mathrm{H})$ & NA & $\begin{array}{l}56.31 \pm 12.59 \text { in } \\
\text { cases } \\
57.24 \pm 10.86 \text { in } \\
\text { controls }\end{array}$ & Yes & 0.01 \\
\hline $\begin{array}{l}\text { Thean } \\
{[22]}\end{array}$ & 2012 & T vs. C & NA & $\begin{array}{c}1.13 \\
{[0.99-1.28]}\end{array}$ & $\begin{array}{l}\text { Singapore } \\
\text { Chinese }\end{array}$ & NA & 991 & $993(\mathrm{P})$ & No & $\begin{array}{c}70 \text { in cases } \\
69 \text { in controls }\end{array}$ & Yes & 0.068 \\
\hline $\begin{array}{l}\text { Tan } \\
{[23]}\end{array}$ & 2016 & T vs. C & 0.28 & $\begin{array}{c}1.05 \\
{[0.92-1.20]}\end{array}$ & Han Chinese & Han & 1030 & $1049(\mathrm{P})$ & No & $\begin{array}{l}60.9 \pm 11.0 \text { in } \\
\text { cases } \\
59.7 \pm 8.2 \text { in } \\
\text { controls }\end{array}$ & Yes & 0.94 \\
\hline
\end{tabular}

MAF, minor allele frequency for T allele in controls; NA, not reported; OR, odds ratio; CI, confidence interval; HWE, Hardy Weinberg equilibrium; $\mathrm{H}$ or $\mathrm{P}$, controls are hospital $(\mathrm{H})$ or population $(\mathrm{P})$ based.

CRC risk in Chinese population. In this study, we aim to evaluate this association in Chinese population.

\section{RESULTS}

\section{Study characteristics}

We selected 4 independent case-control association studies from previous meta-analyses [15-17]. Song et al. selected 12 publications with 25 case-control studies including 19 studies in European population, 1 study in the mixed population, and 5 studies in Asian population, which included 4 studies in Chinese population [15]. Yao et al. selected 21 case-control studies including 14 studies in European population, 1 study in African population, and 6 studies in Asian population, which included 3 studies in Chinese population [16]. Hong et al. selected 12 casecontrol studies, which only included 2 studies in Asian population and Chinese population [17]. We also selected another two independent case-control association studies using Google Scholar and Baidu Scholar databases. All these 6 studies evaluated the potential association between rs4939827 and CRC risk in Chinese population using a total of 12077 samples including 5816 CRC cases and 6261 controls. We described the main characteristics of these 6 studies in Table 1.

\section{Heterogeneity test results}

The heterogeneity test shows that tau^ $2=0, \mathrm{H}=1$ $[1 ; 1.94], I^{\wedge} 2=0 \%[0 \% ; 73.3 \%]$, Cochran's Q statistic $=4.76$, degrees of freedom $=5$, and $P=0.4462$. All these results show no statistically significant heterogeneity.

\section{Meta-analysis results}

We applied the fixed-effect model to perform the meta-analysis. As described in Figure 1, the T allele of rs4939827 was significantly related with an increase $\mathrm{CRC}$ risk $(P=2.22 \mathrm{E}-05, \mathrm{OR}=1.14,95 \%$ CI $1.07-1.21)$ in Chinese population.

\section{Publication bias}

As described in Figure 2, no significant asymmetry was observed in the funnel plot. Linear regression test 
Study

Xiong 2010

Ho 2011

Li 2011

Song 2012

Thean 2012

Tan 2016

Fixed effect model

Heterogeneity: $I$-squared $=0 \%$, tau-squared $=0, p=0.4462$

$$
\begin{array}{rr}
0.16 & 0.0552 \\
0.17 & 0.0794 \\
-0.11 & 0.1820 \\
0.23 & 0.0930 \\
0.12 & 0.0675 \\
0.05 & 0.0674
\end{array}
$$

Odds Ratio

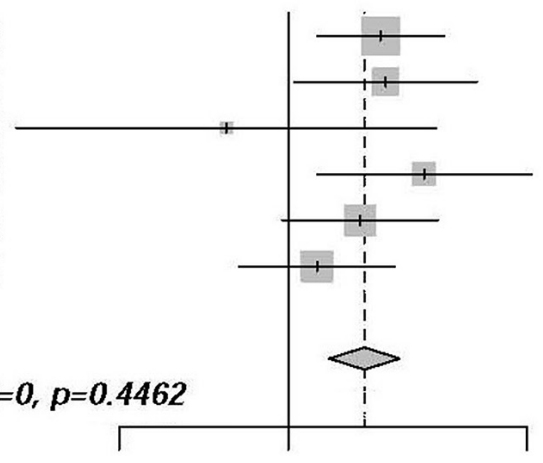

$\begin{array}{lll}0.75 & 1 & 1.5\end{array}$
OR $\quad 95 \%-\mathrm{Cl}$ W(fixed)

$1.17[1.05 ; 1.30] \quad 30.6 \%$

$1.18[1.01 ; 1.38] \quad 14.8 \%$

$0.90[0.63 ; 1.29] \quad 2.8 \%$

$1.26[1.05 ; 1.51] \quad 10.8 \%$

$1.13[0.99 ; 1.29] \quad 20.5 \%$

$1.05[0.92 ; 1.20] \quad 20.5 \%$

$1.14[1.07 ; 1.21] \quad 100 \%$

Figure 1: Forest plot for meta-analysis of rs7014346 variant in Chinese population.

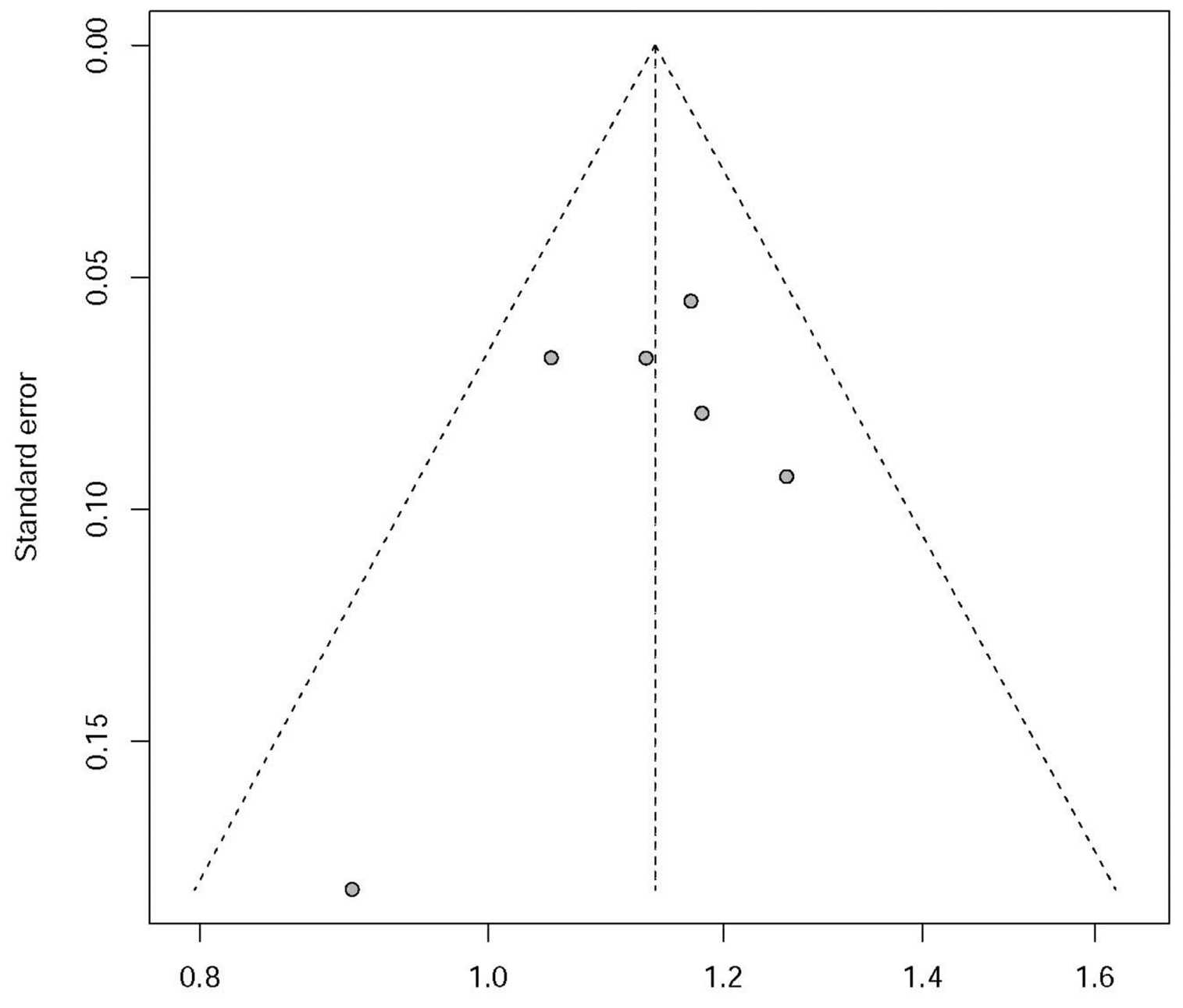

Odds Ratio

Figure 2: Funnel plot for publication bias analysis of rs7014346 in Chinese population. 
of funnel plot asymmetry suggested that there was no significant publication bias in our meta-analysis $P=0.496$.

\section{Subgroup analysis}

In Table 1, we selected six studies including four studies in Han Chinese population, one in Hong Kong Chinese, and one in Singapore Chinese. In 2009, evidence shows substantial genetic variation among Han Chinese population [18]. It would be helpful to consider geographical area. Here, we further performed a subgroup analysis including the Han Chinese subgroup, as well as combined Hong Kong and Singapore Chinese subgroup.

In Han Chinese subgroup, the heterogeneity test shows that $\operatorname{tau}^{\wedge} 2=0.0034 ; \mathrm{H}=1.23[1 ; 2.07] ; \mathrm{I}^{\wedge} 2=$ $33.6 \%[0 \% ; 76.6 \%]$, Cochran's Q statistic $=4.52$, degrees of freedom $=3$, and $P=0.2109$. All these results show no statistically significant heterogeneity. We applied the fixed-effect model to perform the meta-analysis. We identified that the $\mathrm{T}$ allele of rs 4939827 was significantly related with an increase $\mathrm{CRC}$ risk $(P=1.10 \mathrm{E}-03, \mathrm{OR}=1.13$, 95\% CI 1.05-1.22) in Han Chinese subgroup.

In combined Hong Kong and Singapore Chinese subgroup, the heterogeneity test shows that tau^ $2=0$; $\mathrm{H}=1 ; \mathrm{I}^{\wedge} 2=0 \%$, Cochran's $\mathrm{Q}$ statistic $=0.17$, degrees of freedom $=1$, and $P=0.6777$. All these results show no statistically significant heterogeneity. We again applied the fixed-effect model to perform the meta-analysis. We identified that the $\mathrm{T}$ allele of rs 4939827 was significantly related with an increase $\mathrm{CRC}$ risk $(P=6.30 \mathrm{E}-03, \mathrm{OR}=1.15$, $95 \%$ CI 1.04-1.27) in combined Hong Kong and Singapore Chinese subgroup.

\section{DISCUSSION}

Tenesa et al. identified rs4939827 to be associated with $\mathrm{CRC}$ risk with $\mathrm{OR}=1.2$ and $P=7.80 \mathrm{E}-28$ [9]. However following studies reported inconsistent results. Until recently, several meta-analysis studies have been conducted, and reported significant association between rs4939827 and CRC risk [15-17]. In their metaanalysis, Song et performed a stratified analysis. They observed significant heterogeneity in European and Asian populations [15]. In our study, we did not observed significant heterogeneity in Chinese population. In their meta-analysis, Yao et al. selected 21 case-control studies including 14 studies in European population, 1 study in African population, and 6 studies in Asian population, which included 3 studies in Chinese population [16]. A subgroup analysis indicated significant correlation between rs4939827 and CRC risk in the Caucasian group [16]. However, this correlation was not observed in the Asian and African groups [16]. In their meta-analysis, Hong et al. selected 12 case-control studies, which only included 2 studies in Asian population and Chinese population [17]. Their stratified analyses also show that the heterogeneity in the European population is higher than that in the Asian population [17].

Until recently, at least 6 independent case-control association studies have been conducted to investigate the association between rs4939827 and CRC risk in Chinese population. Three studies reported positive association results $[15,19-20]$, and another three studies reported negative association results [21-23]. Until recently, three meta-analysis studies have been conducted [15-17]. However none of these studies evaluated the potential association between rs4939827 and CRC risk in Chinese subgroup analysis [15-17]. In this study, we evaluated this association by a meta-analysis, and identified significant association between rs4939827 and CRC in Chinese population.

In 2009, Chen et al. analyzed 350000 SNPs in over 6000 Han Chinese samples [18]. They identified substantial genetic variation among Han Chinese population [18]. Based on this consideration, we further performed a subgroup analysis in the Han Chinese subgroup, and the combined Hong Kong and Singapore Chinese subgroup. Our results are consistent with previous findings. The heterogeneity in Han Chinese subgroup $\left(\mathrm{I}^{\wedge} 2=33.6 \%\right)$ is higher compared with that in combined Hong Kong and Singapore Chinese subgroup ( $\left(\mathrm{I}^{\wedge} 2=0 \%\right)$. Interestingly, the T allele of rs4939827 was significantly related with an increase CRC risk in both Han Chinese subgroup, and the combined Hong Kong and Singapore Chinese subgroup.

Evidence shows decreased SMAD7 expression in CRC cases [24]. Evidence also supports a role for SMAD7 in sustaining colon tumorigenesis [25]. SMAD7 could block TGF $\beta$ signaling [26]. Boulay et al. previously evaluated the clinical relevance of the deletion of SMAD7, and identified SMAD7 to be a prognostic marker in CRC patients and play an important role in tumor suppression [26]. The loss of SMAD7 could cause carcinoma cells more sensitive [26]. The gain of SMAD7 could cause TGF $\beta$ resistance [26]. Phipps et al. investigated the association between rs4939827 and survival of 2611 individuals with CRC [27]. The results indicated that the minor allele in rs4939827 was significantly associated with reduced overall survival and disease-specific survival. All these findings show that rs 4939827 variant could affect CRC progression [27]. In addition to the rs 4939827 variant, evidence also showed that both rs 12953717 and rs11874392 variants were also associated with risk of CRC [24].

\section{MATERIALS AND METHODS}

\section{Search strategy}

In the PubMed database, we selected the potential studies using the key words 'SMAD7' + 'colorectal cancer' + 'meta' (n=9), and 'rs4939827' + 'colorectal cancer' + 'meta' $(\mathrm{n}=6)$. We also applied Google Scholar 
(https://scholar.google.com/), Chinese National Knowledge Infrastructure (CNKI), Baidu Scholar (http://xueshu.baidu. $\mathrm{com} /$ ) to search manually all associated publications citing the original CRC GWAS [9]. Here, we limit our analysis in Chinese populations including a native or inhabitant of China or a person of Chinese ancestry. There is no limitation on language searched. We included the colorectal cancer cases and excluded the colorectal adenomatous polyps cases.

\section{Data extraction}

The selected studies should provide (1) a casecontrol design in Chinese population; (2) association between rs4939827 and CRC risk; (3) odds ratio (OR) with $95 \%$ confidence interval (CI) for allele model T vs. C; or (4) sufficient data to calculate the OR and 95\% CI for allele model The following items were extracted (1) the name of the first author; (2) the year of publication; (3) the population and ethnicity; (4) the numbers of CRC cases and controls; (5) the OR with 95\% CI; All the possible studies are excluded: abstracts and reviews; and duplicated publications. More detailed information is described in previous studies [15-17, 28-30].

\section{Hardy-Weinberg equilibrium test}

In general, the genetic case-control association studies may be spurious if the distribution of genotypes in the healthy control groups deviates from Hardy-Weinberg equilibrium (HWE). A variant strongly associated with the disease would sometimes show deviance from HWE in case samples [31]. Thus all the selected studies evaluated the potential deviates from HWE in control groups [31]. If the original study provides the control genotype number, we calculated the HWE by a chi-square test [32-33]. If the original study does not provide the control genotype number, we extracted the HWE information from the original studies.

\section{Statistical analysis}

The potential heterogeneity is evaluated by Cochran's Q test [15-17, 28-30, 34-41]. If there is no significant heterogeneity, the pooled OR is calculated by a fixed effect model; otherwise by a random-effect model [15-17, 28-30, 35-41]. Z test is used to determine the significance of pooled OR [28-30]. A funnel plot is used to investigate potential publication bias as described in previous studies [15-17, 28-30, 35-41]. A linear regression based approach is used to test for publication bias, and provide statistical evidence [28-30, 35-41]. All statistical analyses were performed using $\mathrm{R}$, and the significance level is 0.05 .

\section{ACKNOWLEDGMENTS}

This study was funded by Tianjin Health Bureau Science Foundation Key Project (2014KR14), Tianjin
People's Hospital (2016YJZD006), and Tianjin Health and Family Planning Commission (14KG108).

\section{CONFLICTS OF INTEREST}

The authors declare no conflicts of interest.

\section{REFERENCES}

1. Vinson KE, George DC, Fender AW, Bertrand FE, Sigounas G. The Notch pathway in colorectal cancer. Int J Cancer. 2016; 138: 1835-42.

2. De Rosa M, Pace U, Rega D, Costabile V, Duraturo F, Izzo P, Delrio P. Genetics, diagnosis and management of colorectal cancer (Review). Oncol Rep. 2015; 34: 1087-96.

3. Akbari Z, Safari-Alighiarloo N, Taleghani MY, Mirfakhar FS, Asadzadeh Aghdaei H, Vahedi M, Irani Shemirani A, Nazemalhosseini-Mojarad E, Zali MR. Polymorphism of SMAD7 gene (rs2337104) and risk of colorectal cancer in an Iranian population: a case-control study. Gastroenterol Hepatol Bed Bench. 2014; 7: 198-205.

4. Simon MS, Thomson CA, Pettijohn E, Kato I, Rodabough RJ, Lane D, Hubbell FA, O'Sullivan MJ, Adams-Campbell L, Mouton CP, Abrams J, Chlebowski RT. Racial differences in colorectal cancer incidence and mortality in the Women's Health Initiative. Cancer Epidemiol Biomarkers Prev. 2011; 20: 1368-78.

5. Virk R, Gill S, Yoshida E, Radley S, Salh B. Racial differences in the incidence of colorectal cancer. Can J Gastroenterol. 2010; 24: 47-51.

6. Whittemore AS. Colorectal cancer incidence among Chinese in North America and the People's Republic of China: variation with sex, age and anatomical site. Int $\mathrm{J}$ Epidemiol. 1989; 18: 563-8.

7. Lin J, Qiu M, Xu R, Dobs AS. Comparison of survival and clinicopathologic features in colorectal cancer among African American, Caucasian, and Chinese patients treated in the United States: Results from the surveillance epidemiology and end results (SEER) database. Oncotarget. 2015; 6: 33935-43. doi: 10.18632/oncotarget.5223.

8. Tomlinson I, Webb E, Carvajal-Carmona L, Broderick P, Kemp Z, Spain S, Penegar S, Chandler I, Gorman M, Wood W, Barclay E, Lubbe S, Martin L, et al. A genome-wide association scan of tag SNPs identifies a susceptibility variant for colorectal cancer at 8q24.21. Nat Genet. 2007; 39: 984-8.

9. Tenesa A, Farrington SM, Prendergast JG, Porteous ME, Walker M, Haq N, Barnetson RA, Theodoratou E, Cetnarskyj R, Cartwright N, Semple C, Clark AJ, Reid FJ, et al. Genome-wide association scan identifies a colorectal cancer susceptibility locus on 11q23 and replicates risk loci at 8q24 and 18q21. Nat Genet. 2008; 40: 631-7.

10. Tomlinson IP, Webb E, Carvajal-Carmona L, Broderick P, Howarth K, Pittman AM, Spain S, Lubbe S, Walther 
A, Sullivan K, Jaeger E, Fielding S, Rowan A, et al. A genome-wide association study identifies colorectal cancer susceptibility loci on chromosomes 10p14 and 8q23.3. Nat Genet. 2008; 40: 623-30.

11. Houlston RS, Webb E, Broderick P, Pittman AM, Di Bernardo MC, Lubbe S, Chandler I, Vijayakrishnan J, Sullivan K, Penegar S, Carvajal-Carmona L, Howarth K, Jaeger E, et al. Meta-analysis of genome-wide association data identifies four new susceptibility loci for colorectal cancer. Nat Genet. 2008; 40: 1426-35.

12. Schumacher FR, Schmit SL, Jiao S, Edlund CK, Wang H, Zhang B, Hsu L, Huang SC, Fischer CP, Harju JF, Idos GE, Lejbkowicz F, Manion FJ, et al. Genome-wide association study of colorectal cancer identifies six new susceptibility loci. Nat Commun. 2015; 6: 7138.

13. Jia WH, Zhang B, Matsuo K, Shin A, Xiang YB, Jee SH, Kim DH, Ren Z, Cai Q, Long J, Shi J, Wen W, Yang G, et al. Genome-wide association analyses in East Asians identify new susceptibility loci for colorectal cancer. Nat Genet. 2013; 45: 191-6.

14. Zhang B, Jia WH, Matsuda K, Kweon SS, Matsuo K, Xiang YB, Shin A, Jee SH, Kim DH, Cai Q, Long J, Shi J, Wen W, et al. Large-scale genetic study in East Asians identifies six new loci associated with colorectal cancer risk. Nat Genet. 2014; 46: 533-42.

15. Song Q, Zhu B, Hu W, Cheng L, Gong H, Xu B, Zheng X, Zou L, Zhong R, Duan S, Chen W, Rui R, Wu J, et al. A common SMAD7 variant is associated with risk of colorectal cancer: evidence from a case-control study and a meta-analysis. PLoS One. 2012; 7: e33318.

16. Yao K, Hua L, Wei L, Meng J, Hu J. Correlation Between CASC8, SMAD7 Polymorphisms and the Susceptibility to Colorectal Cancer: An Updated Meta-Analysis Based on GWAS Results. Medicine (Baltimore). 2015; 94: e1884.

17. Hong Y, Wu G, Li W, Liu D, He K. A comprehensive metaanalysis of genetic associations between five key SNPs and colorectal cancer risk. Oncotarget. 2016; 7:73945-73959. doi: 10.18632/oncotarget.12154.

18. Chen J, Zheng H, Bei JX, Sun L, Jia WH, Li T, Zhang F, Seielstad M, Zeng YX, Zhang X, Liu J. Genetic structure of the Han Chinese population revealed by genome-wide SNP variation. Am J Hum Genet. 2009; 85: 775-85.

19. Xiong F, Wu C, Bi X, Yu D, Huang L, Xu J, Zhang T, Zhai K, Chang J, Tan W, Cai J, Lin D. Risk of genome-wide association study-identified genetic variants for colorectal cancer in a Chinese population. Cancer Epidemiol Biomarkers Prev. 2010; 19: 1855-61.

20. Ho JW, Choi SC, Lee YF, Hui TC, Cherny SS, GarciaBarcelo MM, Carvajal-Carmona L, Liu R, To SH, Yau TK, Chung CC, Yau CC, Hui SM, et al. Replication study of SNP associations for colorectal cancer in Hong Kong Chinese. Br J Cancer. 2011; 104: 369-75.

21. Li X, Yang XX, Hu NY, Sun JZ, Li FX, Li M. A riskassociated single nucleotide polymorphism of SMAD7 is common to colorectal, gastric, and lung cancers in a Han Chinese population. Mol Biol Rep. 2011; 38: 5093-7.

22. Thean LF, Li HH, Teo YY, Koh WP, Yuan JM, Teoh ML, Koh PK, Tang CL, Cheah PY. Association of Caucasianidentified variants with colorectal cancer risk in Singapore Chinese. PLoS One. 2012; 7: e42407.

23. Tan C, Hu W, Huang Y, Zhou J, Zheng S. Risk of eighteen genome-wide association study-identified genetic variants for colorectal cancer and colorectal adenoma in Han Chinese. Oncotarget. 2016; 7:77651-77663. doi: 10.18632/ oncotarget. 12750 .

24. Jiang X, Castelao JE, Vandenberg D, Carracedo A, Redondo CM, Conti DV, Paredes Cotore JP, Potter JD, Newcomb PA, Passarelli MN, Jenkins MA, Hopper JL, Gallinger S, et al. Genetic variations in SMAD7 are associated with colorectal cancer risk in the colon cancer family registry. PLoS One. 2013; 8: e60464.

25. Stolfi C, De Simone V, Colantoni A, Franze E, Ribichini E, Fantini MC, Caruso R, Monteleone I, Sica GS, Sileri P, MacDonald TT, Pallone F, Monteleone G. A functional role for Smad7 in sustaining colon cancer cell growth and survival. Cell Death Dis. 2014; 5: e1073.

26. Boulay JL, Mild G, Lowy A, Reuter J, Lagrange M, Terracciano L, Laffer U, Herrmann R, Rochlitz C. SMAD7 is a prognostic marker in patients with colorectal cancer. Int J Cancer. 2003; 104: 446-9.

27. Phipps AI, Newcomb PA, Garcia-Albeniz X, Hutter CM, White E, Fuchs CS, Hazra A, Ogino S, Nan H, Ma J, Campbell PT, Figueiredo JC, Peters U, et al. Association between colorectal cancer susceptibility loci and survival time after diagnosis with colorectal cancer. Gastroenterology. 2012; 143: 51-4 e4.

28. Sagoo GS, Little J, Higgins JP. Systematic reviews of genetic association studies. Human Genome Epidemiology Network. PLoS Med. 2009; 6: e28.

29. Kavvoura FK, Ioannidis JP. Methods for meta-analysis in genetic association studies: a review of their potential and pitfalls. Hum Genet. 2008; 123: 1-14.

30. Gwinn M, Ioannidis JP, Little J, Khoury MJ. Editorial: Updated guidance on human genome epidemiology (HuGE) reviews and meta-analyses of genetic associations. Am J Epidemiol. 2014; 180: 559-61.

31. Trikalinos TA, Salanti G, Khoury MJ, Ioannidis JP. Impact of violations and deviations in Hardy-Weinberg equilibrium on postulated gene-disease associations. Am J Epidemiol. 2006; 163: 300-9.

32. Liu G, Zhang S, Cai Z, Ma G, Zhang L, Jiang Y, Feng R, Liao M, Chen Z, Zhao B, Li K. PICALM gene rs3851179 polymorphism contributes to Alzheimer's disease in an Asian population. Neuromolecular Med. 2013; 15: 384-8.

33. Liu G, Zhang L, Feng R, Liao M, Jiang Y, Chen Z, Zhao B, Li K. Lack of association between PICALM rs3851179 polymorphism and Alzheimer's disease in 
Chinese population and APOEepsilon4-negative subgroup. Neurobiol Aging. 2013; 34: 1310 e9-10.

34. Liu G, Xu Y, Jiang Y, Zhang L, Feng R, Jiang Q. PICALM rs3851179 Variant Confers Susceptibility to Alzheimer's Disease in Chinese Population. Mol Neurobiol. 2016; 54:3131-3136.

35. Li Y, Song D, Jiang Y, Wang J, Feng R, Zhang L, Wang G, Chen Z, Wang R, Jiang Q, Liu G. CR1 rs3818361 Polymorphism Contributes to Alzheimer's Disease Susceptibility in Chinese Population. Mol Neurobiol. 2016; 53: 4054-9.

36. Zhang S, Li X, Ma G, Jiang Y, Liao M, Feng R, Zhang L, Liu J, Wang G, Zhao B, Jiang Q, Li K, Liu G. CLU rs9331888 Polymorphism Contributes to Alzheimer's Disease Susceptibility in Caucasian But Not East Asian Populations. Mol Neurobiol. 2016; 53: 1446-51.

37. Li X, Shen N, Zhang S, Liu J, Jiang Q, Liao M, Feng R, Zhang L, Wang G, Ma G, Zhou H, Chen Z, Jiang Y, et al. CD33 rs3865444 Polymorphism Contributes to Alzheimer's Disease Susceptibility in Chinese, European, and North American Populations. Mol Neurobiol. 2015; 52: 414-21.
38. Chen H, Wu G, Jiang Y, Feng R, Liao M, Zhang L, Ma G, Chen Z, Zhao B, Li K, Yu C, Liu G. Analyzing 54,936 Samples Supports the Association Between CD2AP rs9349407 Polymorphism and Alzheimer's Disease Susceptibility. Mol Neurobiol. 2015; 52: 1-7.

39. Zhang S, Zhang D, Jiang Y, Wu L, Shang H, Liu J, Feng R, Liao M, Zhang L, Liu Y, Liu G, Li K. CLU rs2279590 polymorphism contributes to Alzheimer's disease susceptibility in Caucasian and Asian populations. J Neural Transm (Vienna). 2015; 122: 433-9.

40. Shen N, Chen B, Jiang Y, Feng R, Liao M, Zhang L, Li F, Ma G, Chen Z, Zhao B, Li K, Liu G. An Updated Analysis with 85,939 Samples Confirms the Association Between CR1 rs6656401 Polymorphism and Alzheimer's Disease. Mol Neurobiol. 2015; 51: 1017-23.

41. Liu G, Li F, Zhang S, Jiang Y, Ma G, Shang H, Liu J, Feng R, Zhang L, Liao M, Zhao B, Li K. Analyzing large-scale samples confirms the association between the ABCA7 rs3764650 polymorphism and Alzheimer's disease susceptibility. Mol Neurobiol. 2014; 50: 757-64. 